\title{
Trop-2-targeting tetrakis-ranpirnase has potent antitumor activity against triple-negative breast cancer
}

\author{
Donglin Liu ${ }^{1,2^{*}}$, Thomas M Cardillo², Yang Wang ${ }^{2}$, Edmund A Rossi ${ }^{1,2}$, David M Goldenberg ${ }^{1,2,3^{*}}$ \\ and Chien-Hsing Chang ${ }^{1,2}$
}

\begin{abstract}
Background: Ranpirnase (Rap) is an amphibian ribonuclease with reported antitumor activity, minimal toxicity, and negligible immunogenicity in clinical studies, but the unfavorable pharmacokinetics and suboptimal efficacy hampered its further clinical development. To improve the potential of Rap-based therapeutics, we have used the DOCK-AND$\mathrm{LOCK}^{\mathrm{TM}}\left(\mathrm{DNL} \mathrm{T}^{\mathrm{TM}}\right)$ method to construct a class of novel lgG-Rap immunoRNases. In the present study, a pair of these constructs, (Rap) ${ }_{2}-E 1-(\operatorname{Rap})_{2}$ and (Rap) ${ }_{2}-E 1^{*}-(\text { Rap })_{2}$, comprising four copies of Rap linked to the $C_{H} 3$ and $C_{K}$ termini of hRS7 (humanized anti-Trop-2), respectively, were evaluated as potential therapeutics for triple-negative breast cancer (TNBC).

Methods: The DNL-based immunoRNases, (Rap) ${ }_{2}-\mathrm{E} 1-(\operatorname{Rap})_{2}$ and (Rap) ${ }_{2}-\mathrm{E} 1^{*}-(\operatorname{Rap})_{2}$, were characterized and tested for biological activities in vitro on a panel of breast cancer cell lines and in vivo in a MDA-MB-468 xenograft model.

Results: (Rap) $)_{2}-E 1-(\text { Rap })_{2}$ was highly purified $(>95 \%)$, exhibited specific cell binding and rapid internalization in MDA-MB468, a Trop-2-expressing TNBC line, and displayed potent in vitro cytotoxicity ( $E C_{50} \leq 1 \mathrm{nM}$ ) against diverse breast cancer cell lines with moderate to high expression of Trop-2, including MDA-MB-468, BT-20, HCC1806, SKBR-3, and MCF-7. In comparison, structural counterparts of (Rap) ${ }_{2}$-E1-(Rap) ${ }_{2}$, generated by substituting hRS7 with selective non-Trop-2-binding antibodies, such as epratuzumab (anti-CD22), were at least 50-fold less potent than (Rap) $)_{2}$-E1-(Rap) ${ }_{2}$ in MDA-MB-468 and BT-20 cells, both lacking the expression of the cognate antigen. Moreover, (Rap) ${ }_{2}$-E1-(Rap) $)_{2}$ was less effective $\left(E C_{50}>50 \mathrm{nM}\right)$ in MDA-MB-231 (low Trop-2) or HCC1395 (no Trop-2), and did not show any toxicity to human peripheral blood mononuclear cells. In a mouse TNBC model, a significant survival benefit was achieved with (Rap) ${ }_{2}-E 1^{*}-(\operatorname{Rap})_{2}$ when given the maximal tolerated dose.
\end{abstract}

Conclusions: A new class of immunoRNases was generated with enhanced potency for targeted therapy of cancer. The promising results from $(\operatorname{Rap})_{2}-\mathrm{E} 1-(\operatorname{Rap})_{2}$ and $(\operatorname{Rap})_{2}-\mathrm{E} 1^{*}-(\operatorname{Rap})_{2}$ support their further investigation as a potential treatment option for TNBC and other Trop-2-expressing cancers.

Keywords: Ranpirnase, Trop-2, DOCK-AND-LOCK ${ }^{\mathrm{TM}}$, ImmunoRNase, Breast cancer

\section{Background}

Breast cancer is the leading cause of cancer deaths in women and the second most common cancer worldwide after lung cancer [1]. In the USA, about 232,340 new cases of this cancer will be diagnosed and about 39,620 women will die from this disease in 2013 [2]. During the past two decades, important advances have been made

\footnotetext{
* Correspondence: dliu@immunomedics.com; dmg.gscancer@att.net

'IBC Pharmaceuticals, InC., Morris Plains 07950, NJ, USA

${ }^{2}$ Immunomedics, Inc., Morris Plains 07950, NJ, USA

Full list of author information is available at the end of the article
}

in the treatment of hormone receptor (HR)-positive $[3,4]$ and human epidermal growth factor receptor type 2 (HER2)-overexpressing breast cancers [5,6]. However, effective therapies for patients with triple-negative breast cancer (TNBC), which lacks the expression of estrogen receptor (ER), progesterone receptor (PR) and HER2, are still urgently needed [7]. TNBC, afflicting approximately 12 to $17 \%$ of women with breast cancer [8], is a heterogeneous disease with varying prognoses according to molecular, pathological, and clinical factors $[9,10]$. Because of the absence of clear targets like HER2, ER, and 
PR, chemotherapy with doxorubicin plus cyclophosphamide followed by paclitaxel is recommended as the standard of care for systemic treatment of TNBC in the adjuvant setting [11], whereas for patients with metastatic disease, there is no standard first-line agent. To date, various approved agents, including platinum-based compounds, ixabepilone, erlotinib, bevacizumab, cetuximab, and several investigative drugs, in particular, inhibitors of PARP, tyrosine kinases, or mTOR, are being evaluated alone or in combination in different phases of clinical development for TNBC [11]. An arduous challenge in TNBC chemotherapy is primary or acquired drug resistance, resulting in incomplete response, relapse and poor survival.

Rap is a single-chain protein of 104 amino acids (MW $\sim 12 \mathrm{kDa}$ ) originally isolated from the oocytes of Rana pipiens, a Northern leopard frog [12]. Rap exhibits cytostatic and cytotoxic effects on a variety of tumor cell lines in vitro [13], as well as antitumor activity in vivo [14]. The amphibian ribonuclease enters cells via AP-2/ clathrin-mediated endocytosis [15] and once internalized into the cytosol, it selectively degrades tRNA [16], thereby inhibiting protein synthesis and inducing apoptosis [17]. In addition, Rap was shown to enhance both the in vitro and in vivo antitumor activity of vincristine against HT-29 human colorectal cancer cells that had been rendered multidrug-resistant by overexpressing the $m d r 1$ gene [18], and induce caspase-independent cell death in both drug-sensitive and -resistant neuroblastoma cells and tumor xenografts [19]. Clinical studies of Rap in patients with unresectable malignant mesothelioma showed a significant impact on the survival of patients treated with doxorubicin plus Rap compared to doxorubicin alone [20], and a dose-limiting renal toxicity that was reversible upon discontinuation of treatment [21]. Notably, an earlier Phase I trial of Rap in patients with solid cancers reported a lack of untoward immune response upon repeated weekly injections [22].

Trop-2, also known as EGP-1 (epithelial glycoprotein1 ), is a cell-surface glycoprotein overexpressed by a variety of epithelial carcinomas relative to corresponding normal tissues [23]. The expression of Trop-2 was shown to be necessary for tumorigenesis and invasiveness of colon cancer cells, which could be reduced effectively with a polyclonal antibody against the extracellular domain of Trop-2 [24]. More recently, the biological function of Trop-2 in promoting self-renewal and hyperplasia in the prostate was attributed to the accumulation in the nucleus of the intracellular domain of Trop-2 following its cleavage via regulated intramembrane proteolysis [25]. Because of the well-documented clinical evidence in breast cancer [26], colorectal cancer $[27,28]$ and other cancers [29] that overexpressed Trop- 2 is associated with increased tumor aggressiveness, metastasis, and decreased patient survival, there is a growing interest in Trop- 2 as a therapeutic target for solid cancers [30]. For example, the humanized antiTrop-2 monoclonal antibody (mAb), hRS7, is currently under clinical investigation as a drug delivery moiety for patients with advanced epithelial cancers (NCT01631552).

The DOCK-AND-LOCK ${ }^{\mathrm{Tm}}\left(\mathrm{DNL}^{\mathrm{TM}}\right)$ method [31-33] is a platform technology for production of multivalent, multifunctional conjugates by utilizing the naturally occurring interaction between the dimerization and docking domain (DDD) of cAMP-dependent protein kinase A (PKA) and the anchoring domain (AD) of an A-kinase anchoring protein (AKAP). The established strategy involves the use of a specific pair of DDD and AD peptides, termed DDD2 and AD2, to generate two distinct modules, which upon mixing under redox conditions, self-assemble into a DNL conjugate with retained activity and defined composition. We previously reported the antitumor activity of a novel immunotoxin, designated Rap(Q)-hRS7, in Trop-2-expressing cancer cells [34]. The recombinantly-produced $\operatorname{Rap}(\mathrm{Q})$-hRS7 comprises two molecules of Rap(p.N69Q) or N69Q-Rap, a variant of Rap with the putative N-glycosylation site removed by replacing the $69^{\text {th }}$ residue of asparagine (N69) with glutamine $(\mathrm{Q})$, each fused to a light chain of hRS7 at the amino terminus [34].

To further explore the potential of Rap-based immunotoxins, we applied the DNL method to site-specifically tether a dimerized Rap, denoted as (Rap) $)_{2}$, where (Rap) represents Rap-DDD2, at each of the carboxyl termini of either the heavy chain (the $\mathrm{C}_{\mathrm{H}} 3$-format) or the light chain (the $\mathrm{C}_{\mathrm{K}}$-format) of a humanized $\mathrm{IgG}$, resulting in a class of novel immunoconjugates (Table 1) with tetrakis Rap (Figure 1). As exemplified herein by $(\operatorname{Rap})_{2}$-E1$(\text { Rap })_{2}$, comprising four copies of Rap linked to the AD2-fused $\mathrm{C}_{\mathrm{H}} 3$ termini of hRS7 IgG (denoted as E1), and by (Rap) $)_{2}$-E1*-(Rap) ${ }_{2}$, comprising four copies of Rap linked to the AD2-fused $C_{K}$ termini of hRS7 IgG (denoted as E1*), these DNL-based immunoRNases could offer a distinct advantage over their recombinantlyproduced fusion counterparts, such as $\operatorname{Rap}(\mathrm{Q})-\mathrm{hRS7}$, in

Table 1 DNL-Rap conjugates used in the study

\begin{tabular}{|c|c|c|c|}
\hline Code & Target & AD2-module & DDD2-module \\
\hline$(\operatorname{Rap})_{2}-\mathrm{E} 1-(\operatorname{Rap})_{2}$ & Trop-2 & $\mathrm{CH}_{\mathrm{H}} 3-\mathrm{AD} 2-\lg \mathrm{G}-\mathrm{hRS7}$ & Rap-DDD2 \\
\hline$(\operatorname{Rap})_{2}-22-(\operatorname{Rap})_{2}$ & CD22 & $\mathrm{CH}_{\mathrm{H}} 3-\mathrm{AD} 2-\mathrm{lgG}-\mathrm{hLL} 2$ & Rap-DDD2 \\
\hline$(\operatorname{Rap})_{2}-20-(\operatorname{Rap})_{2}$ & CD20 & $C_{H^{3}} 3-A D 2-\lg G-h A 20$ & Rap-DDD2 \\
\hline$(\operatorname{Rap})_{2}-74-(\operatorname{Rap})_{2}$ & CD74 & $C_{H} 3-A D 2-l g G-h L L 1$ & Rap-DDD2 \\
\hline$(\operatorname{Rap})_{2}-\mathrm{C} 2-(\operatorname{Rap})_{2}$ & HLA-DR & $C_{H^{3}} 3-A D 2-l g G-h L 243$ & Rap-DDD2 \\
\hline$(\operatorname{Rap})_{2}-14-(\operatorname{Rap})_{2}$ & CEACAM5 & $\mathrm{C}_{\mathrm{H}} 3-\mathrm{AD} 2-\lg \mathrm{G}-\mathrm{hMN}-14$ & Rap-DDD2 \\
\hline$(\operatorname{Rap})_{2}-\mathrm{E} 1^{*}-(\operatorname{Rap})_{2}$ & Trop-2 & $C_{K^{-}-A D 2-l g G-h R S 7}$ & Rap-DDD2 \\
\hline$(\operatorname{Rap})_{2}-22^{*}-(\operatorname{Rap})_{2}$ & CD22 & $C_{K}-A D 2-\operatorname{lgG}-h L L 2$ & Rap-DDD2 \\
\hline
\end{tabular}




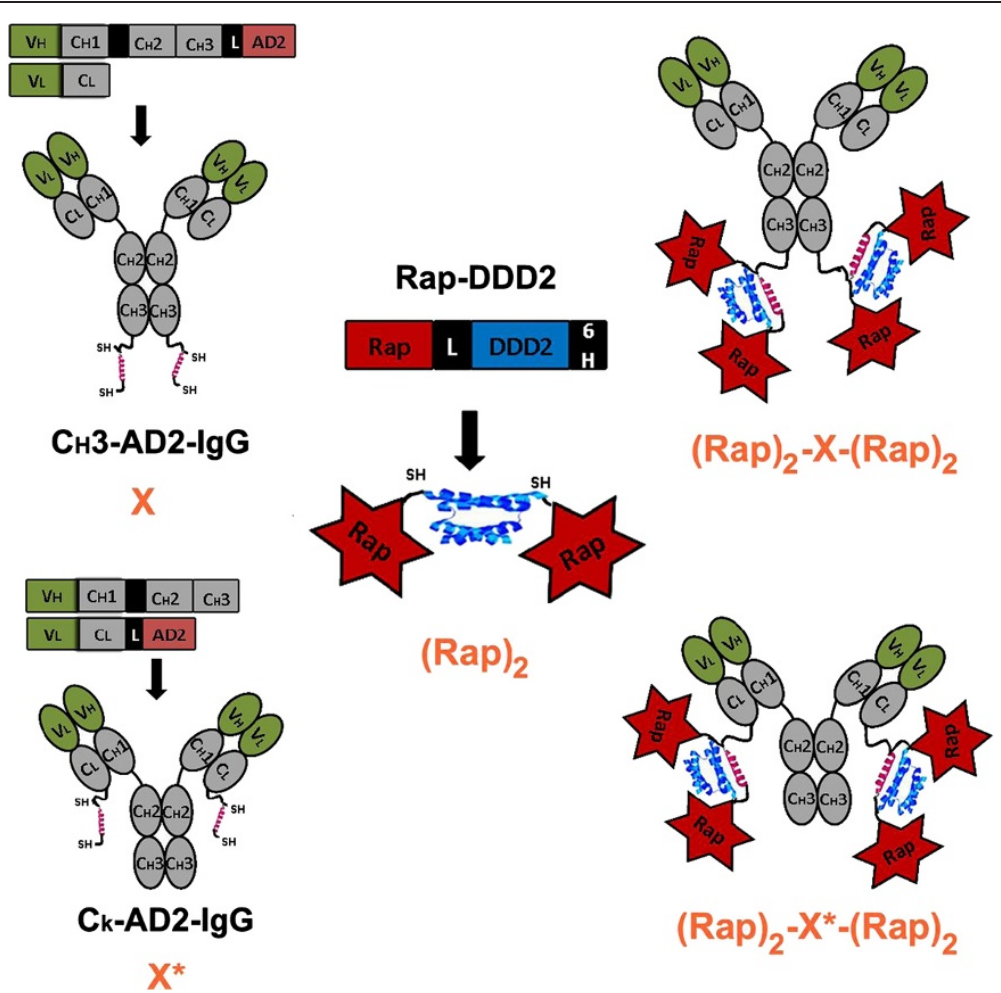

Figure 1 Schematic of expression cassettes and cartoon structures of $C_{H^{3}}$-AD2-lgG (or X), $C_{k}$ 3-AD2-IgG (or X*), Rap-DDD2, (Rap) $(\operatorname{Rap})_{2}-\mathrm{X}-(\operatorname{Rap})_{2}$, and $(\operatorname{Rap})_{2}-\mathbf{X}^{*}-(\operatorname{Rap})_{2}$. DDD2 and AD2 are shown in blue and red, respectively. SH, V, C, G, L, and $6 \mathrm{H}$ represent sulfhydryl groups, variable domain (green), constant region (gray), hinge, linker (GSGGGGSGG), and His tag (HHHHHH), respectively.

improved potency against targeted cancer cells in vitro and tumor xenografts in vivo.

\section{Results}

Preparation and characterization of DNL-Rap conjugates Each DNL-Rap conjugate (Table 1) was obtained with a general protocol involving (i) expression of the respective IgG-AD2 module in myeloma cells, with purification by protein A-based MabSelect affinity chromatography; (ii) expression of Rap-DDD2 in E. coli as inclusion bodies, purified by immobilized metal affinity chromatography under denaturing conditions, and subsequently refolded; (iii) combination of IgG-AD2 with Rap-DDD2 under redox conditions; and (iv) purification of the resulting DNL-Rap conjugate by MabSelect chromatography. Representative results on the SDS-PAGE, size exclusion high-performance liquid chromatography (SEHPLC) and dynamic light scattering analyses demonstrating the molecular purity and integrity of DNL-Rap conjugates are shown for (Rap) $)_{2}$-E1-(Rap) $)_{2}$, (Rap) $)_{2}$-E1*$(\operatorname{Rap})_{2},(\operatorname{Rap})_{2}-22-(\operatorname{Rap})_{2}$, and $(\operatorname{Rap})_{2}-22^{*}-(\operatorname{Rap})_{2}$ (Additional file 1: Figure S1A-E), and summarized below. On nonreducing gel, (Rap) $)_{2}$-E1-(Rap $)_{2}$ was detected as a predominant band (Additional file 1: Figure S1A; lane 6) having the expected size between the monomer and dimer of
$\mathrm{C}_{\mathrm{H}}$ 3-AD2-IgG-hRS7 (Additional file 1: Figure S1A; lane 5); under reducing conditions, only three bands (Additional file 1: Figure S1A; lane 3) were evident, which correspond to the three constituents of (Rap $)_{2}$-E1-(Rap $)_{2}$, namely, Rap-DDD2 (Additional file 1: Figure S1A; lane 1), and the heavy $(\mathrm{H})$ and light $(\mathrm{L})$ chains from $\mathrm{C}_{\mathrm{H}}$ 3-AD2-IgGhRS7 (Additional file 1: Figure S1A; lane 2), indicating the absence of non-product proteins. SE-HPLC analyses of (Rap) ${ }_{2}$-E1-(Rap) ${ }_{2}, \mathrm{C}_{\mathrm{H}} 3$-AD2-IgG-hRS7, and Rap-DDD2 revealed that each existed as a major peak with retention times consistent with their calculated masses (Additional file 1: Figure S1B). Dynamic light scattering analysis of $(\text { Rap })_{2}$-E1-(Rap) $)_{2}$ showed an average diameter of $15.83 \mathrm{~nm}$, with a width of $6.36 \mathrm{~nm}$ (Additional file 1: Figure S1C). Whereas the $\mathrm{C}_{\mathrm{K}^{-}}$and $\mathrm{C}_{\mathrm{H}^{3}}$-formats of $\mathrm{DNL}$ conjugates displayed similar SE-HPLC profiles (Additional file 1: Figure S1D, $(\operatorname{Rap})_{2}-\mathrm{E} 1^{*}-(\operatorname{Rap})_{2}$ vs. $(\operatorname{Rap})_{2}$-E1-(Rap $\left.)_{2}\right)$, they were distinguishable on reducing SDS-PAGE, with the former having a faster moving $\mathrm{H}$ chain and a slower moving $\mathrm{L}$ chain (Additional file 1: Figure S1E, lane 2 vs. lane $4)$. The molecular purity of (Rap $)_{2}-22^{*}$-(Rap $)_{2}$, as well as that of $(\operatorname{Rap})_{2}-22-(\operatorname{Rap})_{2}$, was demonstrated also by reducing SDS-PAGE in Additional file 1: Figure S1E in lanes 2 and 4 , respectively, showing the presence of only three bands in either lane. Further, the three bands in lane 2 
matched the single band of Rap-DDD2 (lane 3) and the double bands of the $\mathrm{H}$ and $\mathrm{L}$ chains from $\mathrm{C}_{\mathrm{K}}$-AD2-IgGhLL2 (lane 1). Likewise, the three bands in lane 4 matched the single band of Rap-DDD2 (lane 3) and the two double bands of $\mathrm{H}$ and $\mathrm{L}$ chains from $\mathrm{C}_{\mathrm{H}} 3-\mathrm{AD} 2-$ IgG-hLL2 (lane 5).

\section{Trop-2 expression on breast cancer cells}

The cell surface expression of Trop-2 on a variety of human breast cancer cell lines was evaluated by flow cytometry using hRS7 IgG as the primary antibody. Seven cell lines were examined, including five basal-like, triplenegative subtypes (MDA-MB-468, MDA-MB-231, BT-20, HCC1806, and HCC1395), one luminal B, HER2-negative subtype (MCF-7), and one HER2-positive subtype (SKBR3). HCC1395 was the only cell line found to be negative, and MDA-MB-231 showed minimal expression (Median fluorescence intensity, MFI $=10.37$ ), while all other lines had moderate $(M F I=40-100)$ to high $(M F I=100-400)$ levels of Trop-2 (Additional file 2: Figure S2 and Additional file 3: Table S1).

\section{In vitro cytotoxicity}

Based on the results of a 4-day MTS assay (Figure 2), $(\text { Rap })_{2}$-E1-(Rap) $)_{2}$ exhibited subnanomolar to nanomolar $\mathrm{EC}_{50}$ values for MDA-MB-468 (0.03 nM), MCF-7 (0.1 $\mathrm{nM})$, BT-20 (0.18 nM), HCC1806 (0.19 nM), and SKBR$3(1.29 \mathrm{nM})$, all of which express moderate to high levels of Trop-2. In comparison, (Rap) $)_{2}$-E1-(Rap) ${ }_{2}$ inhibited proliferation of MDA-MB-231 (low Trop-2) or HCC1395 (negative Trop-2) only at higher concentrations $\left(\mathrm{EC}_{50}>50\right.$ $n M)$. In all cell lines tested, either module $\left(\mathrm{C}_{\mathrm{H}} 3\right.$-AD2IgG-hRS7, Rap-DDD2) alone or the combination of the parental hRS7 IgG with Rap-DDD2 showed negligible cytotoxicity. Besides breast cancer cell lines, potent cytotoxicity with subnanomolar $\mathrm{EC}_{50}$ values was observed for (Rap) $)_{2}$-E1-(Rap) $)_{2}$ in Trop-2-expressing cell lines of other cancers (Additional file 4: Figure S3), including prostate cancer (MDA PCa 2b, PC-3), lung cancer (Calu-3), pancreatic cancer (BxPC-3), and cervical cancer (ME-180), but not in Trop-2-negative cell lines, such as 22Rv1 (prostate cancer). Further studies showed (Rap) $)_{2}$-E1-(Rap) $)_{2}$ to be the most effective in inhibiting the proliferation of MDA-MB-468 or BT-20 compared to other DNL-Rap conjugates that do not target Trop-2 (Figure 3A). The observed $\mathrm{EC}_{50}$ values from the current and previous studies also indicate (Rap) $)_{2}$-E1-(Rap) $)_{2}$ to be considerably more cytotoxic than Rap(Q)-hRS7 in HCC-1806 and BT-20 (Figure 3B), as well as in MDA-MB-468, MCF-7 and SKBR-3 (Table 2). Moreover, the potency of (Rap) $2_{2}^{-}$ E1*-(Rap) ${ }_{2}$, the $\mathrm{C}_{\mathrm{K}^{-}}$-counterpart of (Rap) $)_{2}$-E1-(Rap) $)_{2}$, was comparable to (Rap) $)_{2}$-E1-(Rap $)_{2}$ in HCC-1806, but appeared to be reduced in potency in MDA-MB-468 (Figure 3C).

\section{Cell binding and internalization of (Rap) $)_{2}-\mathrm{E} 1-(\operatorname{Rap})_{2}$}

We compared the binding affinity of (Rap) $)_{2}$-E1-(Rap $)_{2}$ with that of parental hRS7-IgG for MDA-MB-468 cells. As shown in Figure 4A, (Rap) ${ }_{2}$-E1-(Rap $)_{2}$ and hRS7-IgG bound equivalently to MDA-MB-468 at all three concentrations examined, indicating the avidity of $(\mathrm{Rap})_{2}$-E1$(\text { Rap })_{2}$ for Trop-2 is not compromised. We also examined the intracellular distribution of (Rap) $)_{2}$-E1-(Rap $)_{2}$ in MDAMB-468, and found it was effectively internalized at $37^{\circ} \mathrm{C}$ after 2-h incubation, and existed mostly as punctas within the cytoplasm (Figure 4B).

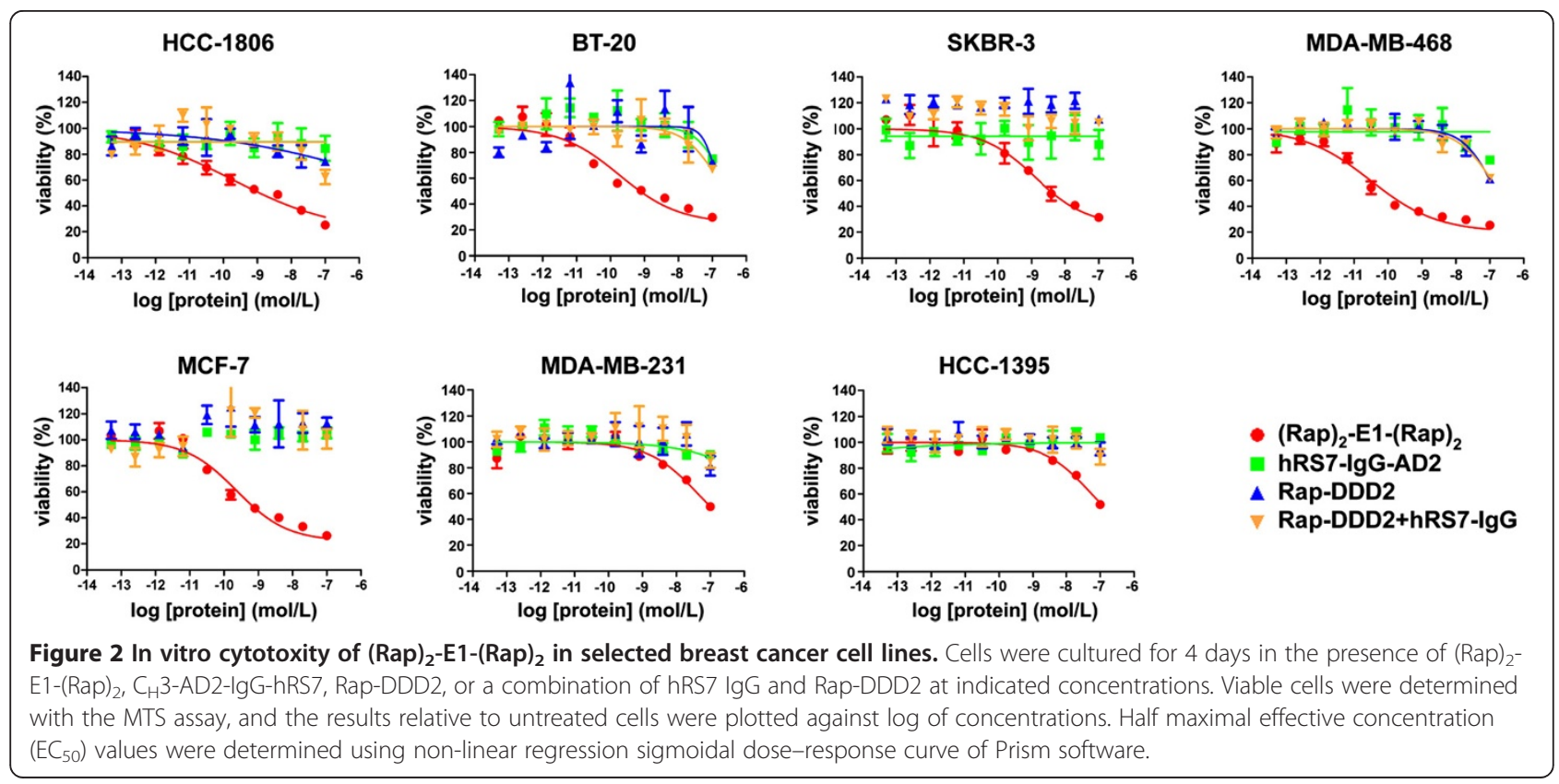




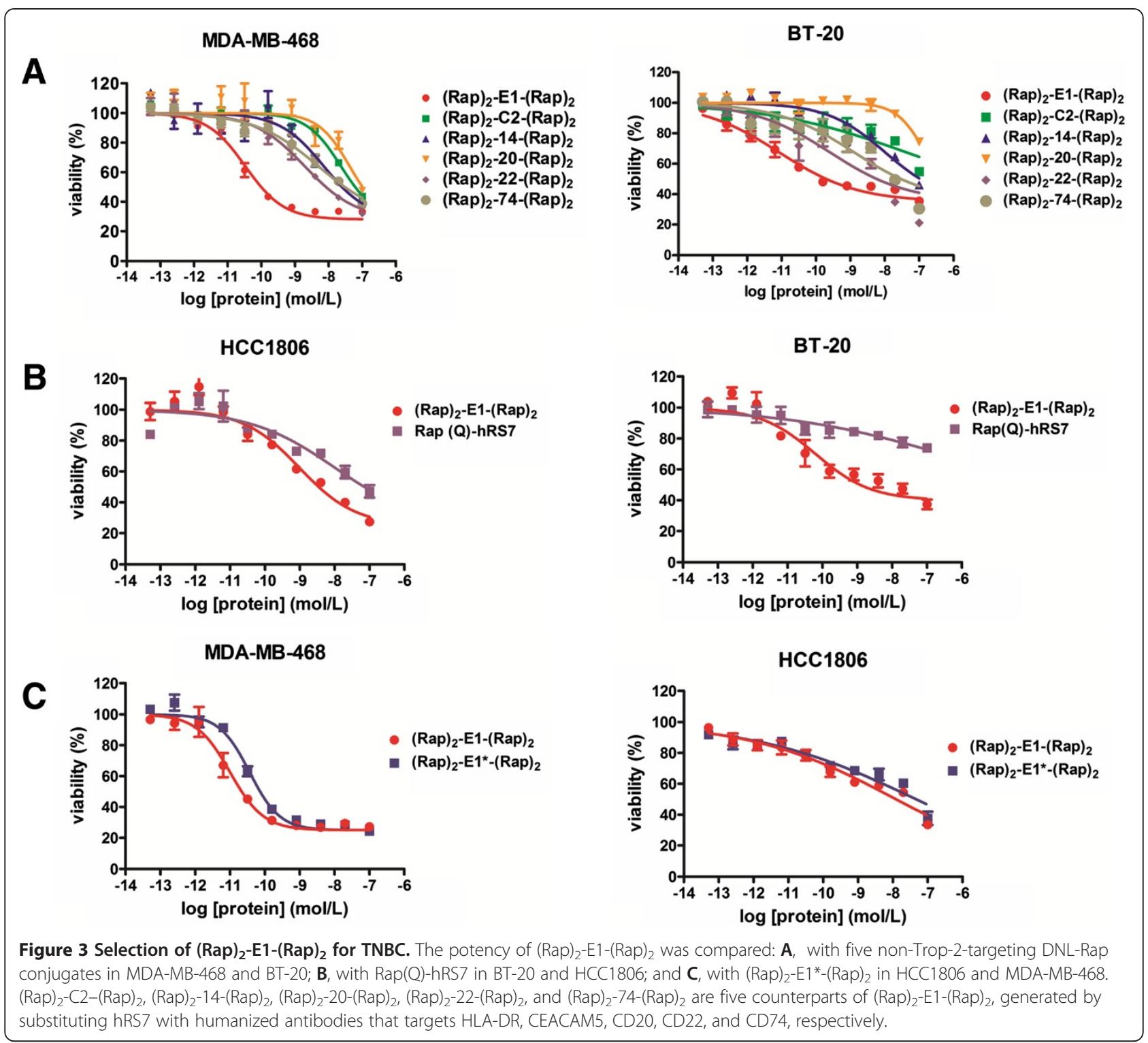

Minimal toxicity of (Rap) $)_{2}$-E1-(Rap $)_{2}$ on hematological cells The toxicity of (Rap) $)_{2}$-E1-(Rap) ${ }_{2}$ to hematological cells was assessed on human peripheral blood mononuclear cells (PBMC) obtained from two healthy donors, following treatment with $(\operatorname{Rap})_{2}$-E1-(Rap $)_{2}$ at $0.1,1$, and 10 $\mathrm{nM}$ for $18 \mathrm{~h}$. Treatment with $(\operatorname{Rap})_{2}-\mathrm{E} 1-(\operatorname{Rap})_{2}$ had nearly the same amount of apoptotic and dead cells as the untreated control (Additional file 5: Figure S4), indicating that $(\operatorname{Rap})_{2}-\mathrm{E} 1-(\operatorname{Rap})_{2}$ is not toxic to PBMC at concentrations up to $10 \mathrm{nM}$.

MTD in nude mice

Among the four groups (20,40,60 or $80 \mu \mathrm{g})$ tested, only those mice that received the four injections of (Rap) $)_{2}$ $22 *(\operatorname{Rap})_{2}$ at $20 \mu \mathrm{g}$ survived without acute toxicity or death. One of the three animals lost $\sim 12 \%$ of its body

Table 2 Comparison of in vitro potency of (Rap) $)_{2}$-E1-(Rap) 2 vs. Rap(Q)-hRS7

\begin{tabular}{|c|c|c|c|c|c|c|c|}
\hline \multirow[t]{2}{*}{ Agents } & \multicolumn{7}{|l|}{$\mathrm{EC}_{50}(\mathrm{nM})^{\mathrm{a}}$} \\
\hline & MDA-MB-468 & MCF-7 & SKBR-3 & HCC1806 & BT-20 & MDA-MB-231 & HCC1395 \\
\hline$(\operatorname{Rap})_{2}-\mathrm{E} 1-(\operatorname{Rap})_{2}$ & 0.03 & 0.1 & 1.29 & 0.19 & 0.18 & $>50$ & $\sim 100$ \\
\hline Rap(Q)-hRS7 & $3.8^{\mathrm{b}}$ & $>100^{b}$ & $>100^{b}$ & 10.1 & $>100$ & $N^{c}$ & $N^{c}$ \\
\hline
\end{tabular}

${ }^{a}$ Half maximal effective concentration; ${ }^{b}$ From previous results [34]; ${ }^{c}$ Not determined. 

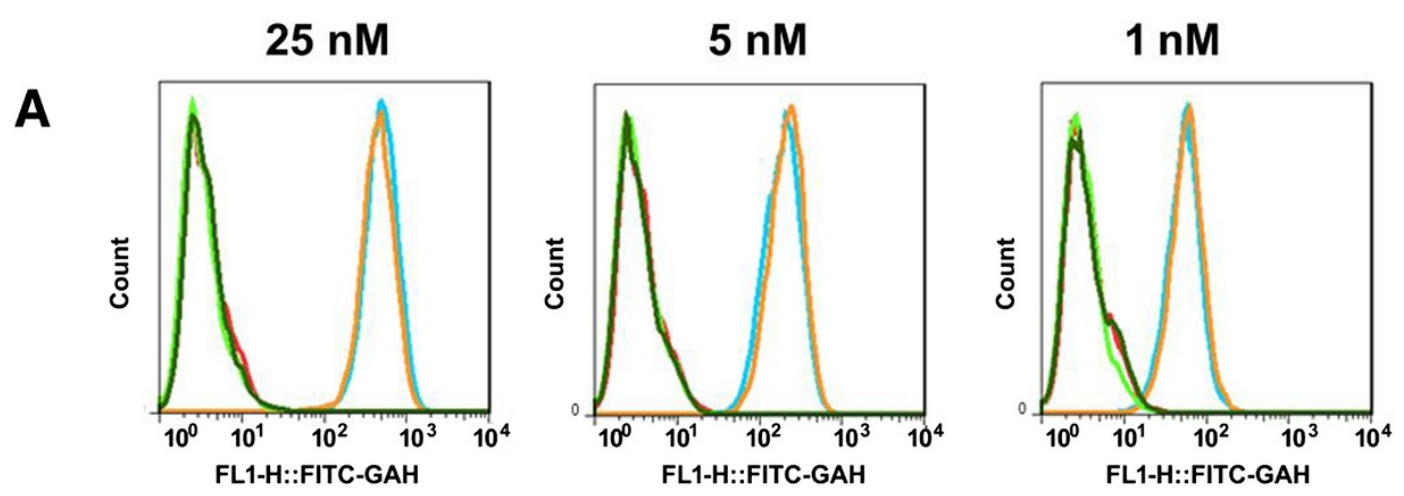

\begin{tabular}{|l|l|l|l|}
\hline \multirow{2}{*}{} & \multicolumn{3}{|c|}{ Mean fluorescence intensity } \\
\cline { 2 - 4 } & $25 \mathrm{nM}$ & $5 \mathrm{nM}$ & $1 \mathrm{nM}$ \\
\hline FITC-GAH alone & 4.24 & 4.24 & 4.24 \\
\hline hRS7-IgG & 533 & 211.33 & 58.63 \\
\hline${\left.\text { (Rap })_{2} \text {-E1-(Rap) }\right)_{2}}_{\text {hA20-IgG }}$ & 479.33 & 231.67 & 63 \\
\hline (Rap) ${ }_{2}$-20-(Rap $)_{2}$ & 3.95 & 3.92 & 3.74 \\
\hline
\end{tabular}

B
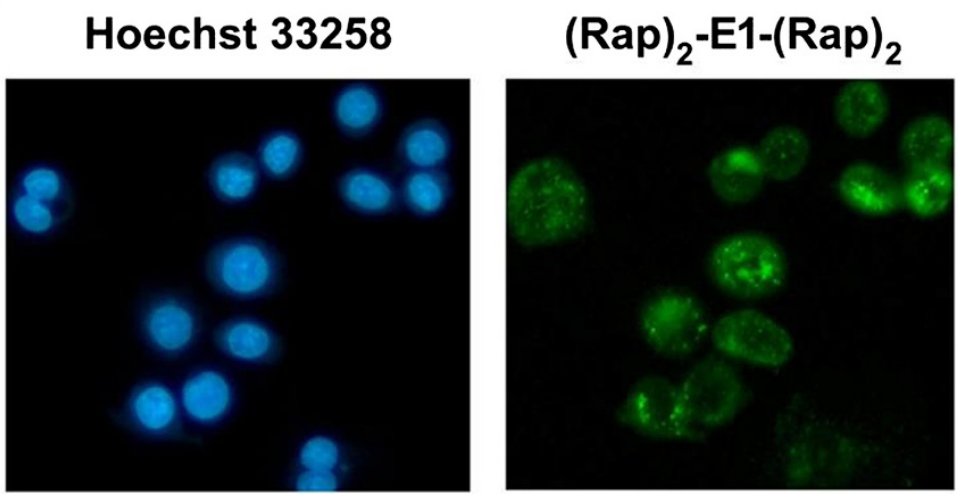

\section{Transferrin}

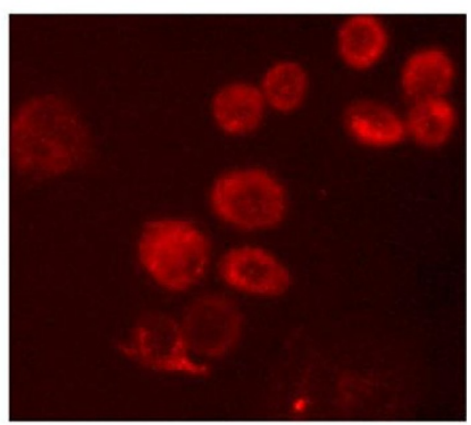

All three images merged Green and red images merged
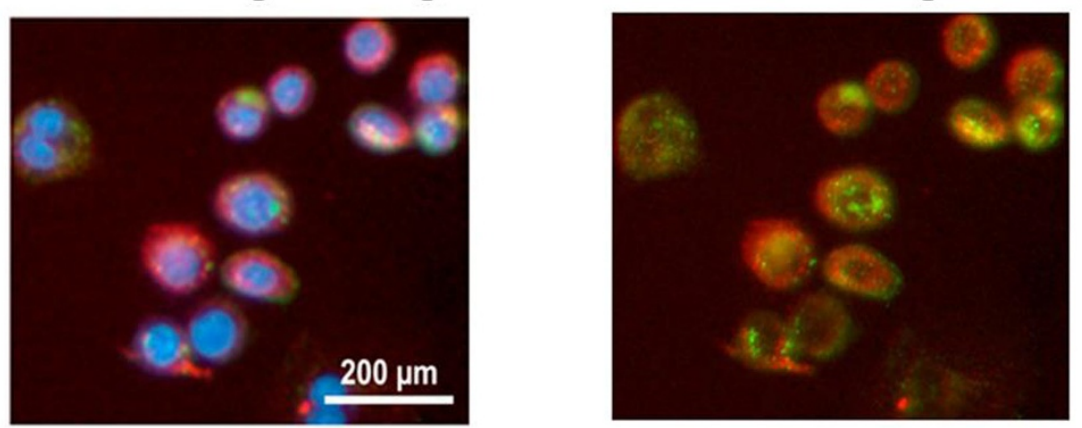

Figure 4 (See legend on next page.) 
(See figure on previous page.)

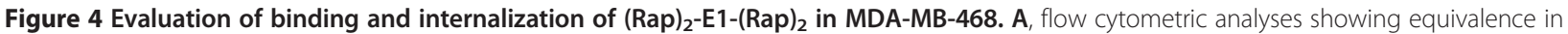
binding of (Rap) $)_{2}$-E1-(Rap) 2 and hRS7 lgG to MDA-MB-468 at three concentrations (1, 5 and 25 nM). The CD20-targeting (Rap) 2 -20-(Rap) 2 and hA20 served as negative controls; $\mathbf{B}$, following incubation, $\mathrm{pH} 2.5$ treatment, and fixation as described in the Methods, cells were stained with GAH-Alexa Fluor 488 (green) to detect intracellular (Rap) 2 -E1-(Rap)2, and also with Hoechst 33258 (blue) and human transferrin-conjugated Alexa Fluor 568 (red) to reveal the nucleus and endosomes, respectively.

weight by day 4 , but this was only transient, and by day 7 had regained much of this lost weight. All three mice survived to the end of the study on day 56. The maximum tolerated dose (MTD) of a DNL-Rap conjugate was therefore defined as $20 \mu \mathrm{g}$, administered i.v. every four days for four times $(\mathrm{q} 4 \mathrm{~d} \times 4)$. Although we have not formally determined the MTD of (Rap) $)_{2}-\mathrm{E} 1 *-(\operatorname{Rap})_{2}$ or other DNL-Rap conjugates in similar studies, subsequent experiments in tumor-bearing mice indicated that the animals also tolerated $(\operatorname{Rap})_{2}-\mathrm{E} 1 *(\operatorname{Rap})_{2}$ or $(\operatorname{Rap})_{2}-20$ $(\operatorname{Rap})_{2}$ when given the dosing regimen of $20 \mu \mathrm{g}$ i.v., q4dx4.

\section{In vivo activity}

We selected (Rap) $)_{2}-\mathrm{E} 1^{*}$-(Rap) $)_{2}$ for in vivo studies because the $\mathrm{C}_{\mathrm{K}}$-based conjugates exhibited superior Fc-effector functions in vitro, as well as improved pharmacokinetics, stability, and activity in vivo, as demonstrated for two types of DNL conjugates having a similar structure to IgG-Rap; namely, a bispecific hexavalent antibody comprising a pair of dimeric Fab linked to an IgG, and a multivalent immunocytokine comprising a pair of dimeric IFN- $\alpha$ linked to an IgG [35].

In the TNBC model of mice bearing MDA-MB-468 tumors, all mice tolerated the two cycles of treatment with no mouse losing more than $9 \%$ of starting body weight during dosing (Additional file 6: Figure S5). Based on area under the curve (AUC) determined on day 48, $(\operatorname{Rap})_{2}-\mathrm{E} 1$ *-(Rap $)_{2}$ significantly inhibited tumor growth compared to the saline control (Figure 5A; $P=0.0254$ ). In addition, a significant survival benefit (Figure 5B), as indicated by the median survival time, was obtained with the $(\operatorname{Rap})_{2}-\mathrm{E} 1 *$-(Rap) $)_{2}$ group (98 days) when compared to either the saline group (63 days; $P<0.0070$ ) or the $(\text { Rap })_{2}-22^{*}-(\text { Rap })_{2}$ group (84 days; $\left.P<0.0438\right)$. Notably, 2 of 8 mice in the $(\operatorname{Rap})_{2}$-E1*-(Rap $)_{2}$ group were tumorfree when the experiment ended on day 105.

To further demonstrate the targeting specificity of $(\operatorname{Rap})_{2}-\mathrm{E} 1 *-(\operatorname{Rap})_{2}$ vs. $(\operatorname{Rap})_{2}-22 \%$-(Rap $)_{2}$, we performed another study to compare their potency in a CD22expressing, but Trop-2-negative, tumor model. Mice bearing disseminated Burkitt-NHL (Daudi) were treated 7 days after the animals were administered the cells to ensure a large tumor-burden at the time of therapy initiation (Figure 5C). All mice in the saline control group succumbed to disease progression by day 32 (median $=32$ days). Likewise, mice treated with the
MTD of $(\operatorname{Rap})_{2}$-E1*-(Rap) $)_{2}$ were all dead by day 48 (median $=36$ days). Conversely, all mice that received the MTD of (Rap) $)_{2}-22 *(\operatorname{Rap})_{2}$ or half this dose were still alive and tumor-free at the time the experiment was ended on day 84 . Overall, treatment with (Rap $)_{2}-22 *$-(Rap $)_{2}$ resulted in a significant survival benefit when compared to the saline or treatment control $(P<0.0034)$.

\section{Discussion}

Rap is a promising antitumor toxin with several attractive properties, including minimal toxicity, negligible immunogenicity, and the potential to overcome multiple drug resistance via unusual mechanisms of internalization and cytotoxicity. Over the years, we have made considerable progress to enhance the potency of Rap by targeting it to cancer cells expressing CD22, CD74 and Trop-2, as exemplified by LL2-onconase [36], Rap-hLL1 [37], and $\operatorname{Rap}(\mathrm{Q})-\mathrm{hRS7}$ [34], respectively, but have also encountered difficulty in scaled-up production of these prototypes due to relatively low productivity of RaphLL1 or Rap(Q)-hRS7 in mammalian cell cultures. We believe the $\mathrm{DNL}^{\mathrm{TM}}$ platform technology, which conveniently tethers four copies of Rap to the C-terminus of different IgG modules, has key production advantages for Rap-based immunotoxins. Moreover, these DNL-Rap conjugates ensure targeted delivery of Rap with significantly improved potency in cancer cells expressing the cognate antigens, as exemplified by $(\operatorname{Rap})_{2}$-E1-(Rap $)_{2}$ in the current study with breast cancer cell lines. It is noteworthy that in MDA-MB-468 cells with a moderate level of Trop-2, the cytotoxicity of the DNL-generated (Rap) ${ }_{2}$ $\mathrm{E} 1-(\operatorname{Rap})_{2} \quad\left(\mathrm{EC}_{50}=0.03 \mathrm{nM}\right)$ was 100 -fold more potent than the recombinant $\operatorname{Rap}(\mathrm{Q})-\mathrm{hRS7}\left(\mathrm{EC}_{50}=3.8 \mathrm{nM}\right)$, and 3,000-fold more potent than unconjugated Rap $\left(\mathrm{EC}_{50}>100 \mathrm{nM}\right)$. On the other hand, (Rap) $)_{2}-\mathrm{E} 1-(\operatorname{Rap})_{2}$ inhibited the proliferation of Trop-2-negative HCC1395 cells only at much higher concentrations $\left(\mathrm{EC}_{50}>50 \mathrm{nM}\right)$ and yet was not toxic to PBMCs, indicating the likely existence of a relatively large therapeutic window.

We reported previously that in MDA-MB-468 cells, Rap(Q)-hRS7 co-localized with human transferrin in the endosomes after a $2-\mathrm{h}$ incubation at $37^{\circ} \mathrm{C}$ [34], whereas in the current study under the same conditions, (Rap) $)_{2}$ E1-(Rap) $)_{2}$ did not co-localize with human transferrin in the endosomes, suggesting a different internalization pathway, which may explain its greater potency in MDA-MB-468 than observed for Rap(Q)-hRS7. 


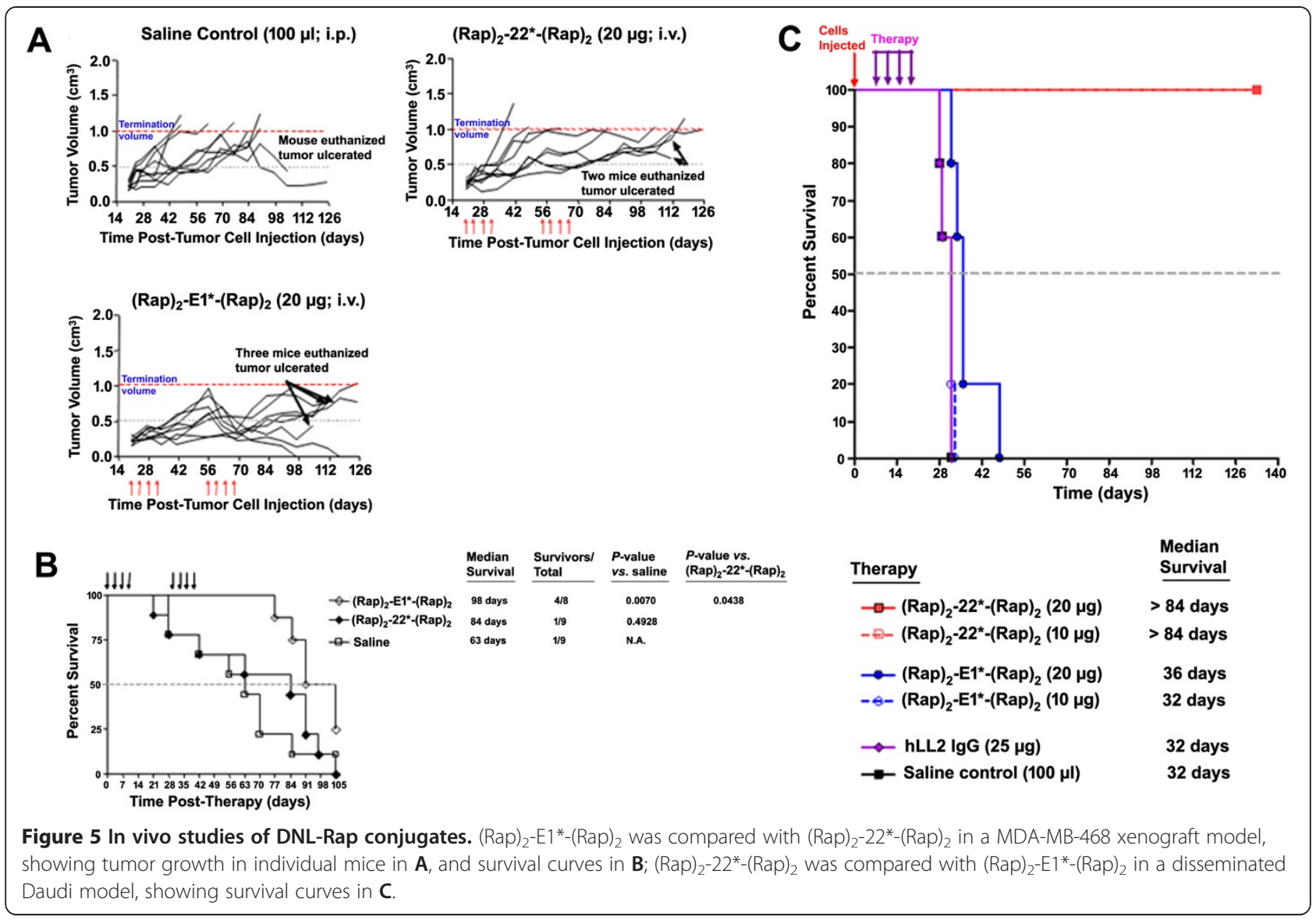

We noted that unlike the bispecific hexavalent antibodies, for which the $\mathrm{C}_{\mathrm{K}}$-format was demonstrated to be superior to the $\mathrm{C}_{\mathrm{H}} 3$-format [35], the potential advantage of a $\mathrm{C}_{\mathrm{K}}$-format of DNL-Rap vs. its $\mathrm{C}_{\mathrm{H}} 3$-counterpart is not readily apparent from the present data, and will require further studies.

The potency and specificity of DNL-Rap conjugates for targeted cancer therapy is also supported by the statistically significant antitumor activity of $(\operatorname{Rap})_{2}$-E1*-(Rap $)_{2}$ in suppressing growth of MDA-MB-468 xenografts, and by the observed cure of all five mice with disseminated Daudi lymphoma following treatment with four 20- $\mu \mathrm{g}$ doses of (Rap) $)_{2}-22 *-(\operatorname{Rap})_{2}$ given 4 days apart, both of which should reduce the potential concern that the larger size of DNL-Rap conjugates would negatively impact their in vivo efficacy, particularly in solid cancer, due to poor penetration.

Although hRS7 binds to selected human epithelial cells, recent studies with a drug conjugate of hRS7 in cynomolgus monkeys, whose tissues cross-react with hRS7, showed that tolerated doses occurred at clinically-relevant concentrations, and that dose-limiting toxicities to normal tissues were no different from those reported previously with the free drug [38]. These data suggest that having Rap attached to hRS7 may not add substantially its toxicity to normal tissues, and that (Rap) $)_{2}$-E1-(Rap $)_{2}$ or $(\operatorname{Rap})_{2}$-E1*-(Rap) ${ }_{2}$ may be tolerated at clinically-relevant concentrations. In addition, because the structural motif $(\mathrm{x}) \mathrm{D}(\mathrm{y})$ identified to be responsible for the binding of ricin A-chain or interleukin-2 to endothelial cells is absent in the native sequence of Rap, and hRS7 is not cross-reactive with human endothelial cells, we consider the likelihood of $(\operatorname{Rap})_{2}$-E1-(Rap) $)_{2}$ or $(\operatorname{Rap})_{2}$-E1*-(Rap) $)_{2}$ causing vascular leak syndrome as remote. Regarding the immunogenicity of DNL-Rap conjugates, it needs to be addressed in a relevant species as well as in future human studies.

\section{Conclusions}

We have generated a new class of immunoRNases and demonstrated their potential for targeted therapy of cancer. These promising results warrant further studies to advance the development of (Rap) $)_{2}$-E1-(Rap $)_{2}$ or (Rap) $)_{2}$ E1*-(Rap $)_{2}$, in particular, and other DNL-Rap conjugates, in general, as potential novel therapeutics for triplenegative breast cancer or other Trop-2-expressing cancers.

\section{Methods}

Antibodies and reagents

Humanized antibodies including hA20 (anti-CD20, veltuzumab), hLL2 (anti-CD22, epratuzumab), and hRS7 
(anti-Trop-2) were obtained in-house. FITC-labeled goat anti-human IgG (FITC-GAH) was purchased from Jackson ImmunoResearch Laboratories (West Grove, PA). Annexin V Alexa Fluor 488 conjugate and 7-AAD were purchased from Life Technologies Corporation (Grand Island, NY).

\section{Expression and purification of DNL modules}

To produce the Rap-DDD2 module used for DNL conjugation, a DNA fragment encoding Rap and a GGGGS linker sequence was amplified by PCR from $r P R L 2 \# 26$ plasmid [34] and inserted into the MscI and XhoI restriction sites of the $p E T-26 b$ vector to generate rap-GS$p E T 26 b$. Subsequently, the DDD2 coding sequence was amplified by PCR from IFN 2 2b-DDD2-pdHL2 [33] and inserted into XhoI site of $r a p-p E T 26 b$ to generate the expression vector rap-GS-DDD2-pET26b. Competent Rosetta-pLysS cells (EMD Millipore, Billerica, MA) were transformed with rap-GS-DDD2-pET26b and cultured in shaker flasks at $37^{\circ} \mathrm{C}$ in Difco $2 x Y T$ broth (Becton Dickinson, Franklin Lakes, NJ), supplemented with 100 $\mu \mathrm{g} / \mathrm{mL}$ kanamycin sulfate and $34 \mu \mathrm{g} / \mathrm{mL}$ chloramphenicol. When the cell density reached $\mathrm{OD}_{600}=1.0$, cultures were switched to $30^{\circ} \mathrm{C}$ and protein expression was induced with $0.4 \mathrm{mM}$ IPTG for $4 \mathrm{~h}$. Cell pellets were frozen, thawed and homogenized in a lysis buffer comprising 2\% Triton X-100, $5 \mathrm{mM} \mathrm{MgSO}_{4}, 10$ units/mL benzonase (Novagen EMD Millipore), $100 \mu \mathrm{M}$ 4-(2-aminoethyl) benzenesulfonyl fluoride (Sigma-Aldrich, St. Louis, MO), and $20 \mathrm{mM}$ Tris- $\mathrm{HCl}, \mathrm{pH}$ 8.0. The insoluble material, containing inclusion bodies, was pelleted by centrifugation, re-homogenized in $1 \%$ Triton X-100 in PBS, and re-pelleted. Inclusion bodies were solubilized in $6 \mathrm{M}$ guanidine- $\mathrm{HCl}, 100 \mathrm{mM} \mathrm{Na}$-phosphate, $\mathrm{pH}$ 8.0, and applied to a His-Select affinity column (GE Healthcare, Piscataway, NJ). The denatured protein was

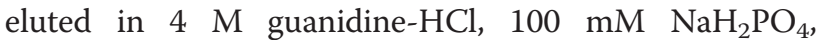
$\mathrm{pH}$ 4.5. The eluate was neutralized with $3 \mathrm{M}$ Tris- $\mathrm{HCl}$, $\mathrm{pH}$ 8.6, added dithioerythreitol (DTE) to $60 \mathrm{mM}$, and held at room temperature overnight, to which was added rapidly 10 -fold volume of $0.5 \mathrm{M}$ arginine, $20 \mathrm{mM}$ oxidized glutathione, $2 \mathrm{mM}$ EDTA,100 mM Tris, $\mathrm{pH}$ 8.0, followed by dialysis against $5 \mathrm{~L}$ of a renaturation buffer (0.5 $\mathrm{M}$ arginine, $2 \mathrm{mM}$ oxidized glutathione, $0.6 \mathrm{mM}$ DTE, 2 mM EDTA, $20 \mathrm{mM}$ Tris, pH 8.0) for $72 \mathrm{~h}$ at $4^{\circ} \mathrm{C}$, and subsequently against PBS buffer.

Expression vectors for the $\mathrm{C}_{\mathrm{H}} 3$-AD2-IgG modules were engineered from cognate IgG-pdHL2 expression vectors, as described previously [39]. The $\mathrm{C}_{\mathrm{K}}$-AD2-IgG modules were generated by fusing AD2 and a hinge linker sequence to the C-terminal end of the kappa light chain [35]. These modules were produced in myeloma cell culture of SpESFX-10 cells [40] and isolated from culture broths using MabSelect affinity chromatography (GE Healthcare).

\section{DNL conjugation}

The Rap-DDD2 module was reacted with a $\mathrm{C}_{\mathrm{H}} 3$-AD2-IgG or a $\mathrm{C}_{\mathrm{K}}$-AD2-IgG of choice to generate a panel of DNLRap conjugates, as listed in Table 1, with the structures of the $\mathrm{C}_{\mathrm{H}} 3$ - and $\mathrm{C}_{\mathrm{K}}$-types shown schematically in Figure 1. Typically, an AD2-IgG was combined with approximately two mole-equivalents of Rap-DDD2, followed by the addition of reduced glutathione to a final concentration of $2 \mathrm{mM}$. After incubation at room temperature overnight, oxidized glutathione was added to a final concentration of $4 \mathrm{mM}$ on the next day, the incubation continued for another $24 \mathrm{~h}$, and the resulting DNL-Rap conjugate was purified by MabSelect affinity chromatography.

\section{Molecular characterization of DNL-Rap conjugates}

SDS-PAGE was performed under reducing and nonreducing conditions using 4-20\% Tris-Glycine gels (Lonza, Allendale, NJ). SE-HPLC was performed at the flow rate $1 \mathrm{ml} / \mathrm{min}$ and detection wavelength $280 \mathrm{~nm}$ using an Alliance HPLC System with a BioSuite 250, 4$\mu \mathrm{m}$ UHR SEC column (Waters Corp. Milford, MA). Particle size analysis was performed by a contract laboratory (Microtrac, Largo, FL).

\section{Cell lines}

All cell lines were purchased from the American Type Culture Collection (ATCC, Manassas, VA), which include seven of breast cancer (MCF-7, MDA-MB-468, MDA-MB-231, HCC1806, HCC1395, BT-20, SKBR-3), three of prostate cancer (MDA PCa 2b, PC-3, 22Rv1), one of pancreatic cancer (BxPC-3), one of lung cancer (Calu-3), one of cervical cancer (ME-180), and one of non-Hodgkin lymphoma (Daudi). Each cell line was maintained according to the recommendations of ATCC and routinely tested for mycoplasma using MycoAlert ${ }^{\circ}$ Mycoplasma Detection Kit (Lonza).

\section{Internalization studies by fluorescence microscopy}

MDA-MB-468 cells were placed at 3000 cells/well in 8well, Lab-Tek II chamber slides (Nalge Nunc International) and incubated with $40 \mathrm{nM}$ of (Rap) $)_{2}$-E1-(Rap $)_{2}$ and 1:200 diluted human transferrin (hTf) conjugated to Alexa Fluor 568 (T-23365, Life Technologies Corporation) at $37^{\circ} \mathrm{C}$ for $2 \mathrm{~h}$. After washing twice in PBS plus $2 \% \mathrm{BSA}$, cells were treated in $0.1 \mathrm{M}$ glycine buffer $(\mathrm{pH} 2.5)$ for $2 \mathrm{~min}$, and then fixed in $4 \%$ formalin for $15 \mathrm{~min}$, followed by Alexa Fluor 488-conjugated goat anti-human IgG for 15 min. After washing twice with PBS, cells were stained with Hoechst 33258 for $5 \mathrm{~min}$ and examined under a fluorescence microscope.

\section{Flow cytometry}

Cells were trypsinized briefly, washed, re-suspended in $1 \%$ BSA-PBS, incubated with hRS7 or hA20 IgG, and 
detected with FITC-GAH. All incubations were $45 \mathrm{~min}$ at $4^{\circ} \mathrm{C}$ with $1 \%$ BSA-PBS washes between incubations. Cell binding was measured by flow cytometry using a BD FACSCalibur (BD Biosciences, San Jose, CA).

\section{In vitro proliferation}

Cells were seeded in 96-well plates at 1,000-2,000 cells/ well and held at $37^{\circ} \mathrm{C}$ overnight prior to incubation with the indicated agents for 4 days. Viable cells were measured using MTS substrate Cell Titer96 ${ }^{\circ}$ AQueous One Solution (Promega, Madison, WI).

\section{Toxicity in human PBMC}

Buffy coats from healthy donors were purchased from the Blood Center of New Jersey, with approval by the New England Institutional Review Board. PBMCs were isolated from buffy coats by standard density-gradient centrifugation over Ficoll-Paque, and treated with (Rap) ${ }_{2}$ E1-(Rap) $)_{2}$ at $37^{\circ} \mathrm{C}$ in $5 \% \mathrm{CO}_{2}$ for $16 \mathrm{~h}$. After incubation, the cells were stained with Alexa Fluor ${ }^{\circ}$ 488-labeled annexin $\mathrm{V}$, then with 7-aminoactinomycin-D, and analyzed by flow cytometry.

\section{Determination of maximal tolerated dose (MTD) in mice}

Female athymic nude mice ( 8 weeks old) were divided into four groups of three each, with each group receiving $(\operatorname{Rap})_{2}-22^{*}-(\operatorname{Rap})_{2}$ at one of four different doses (20, 40, 60 or $80 \mu \mathrm{g}$ ). Animals were dosed i.v. every four days for a total of four injections ( $\mathrm{q} 4 \mathrm{dx} 4)$. Toxicity was assessed by daily observations and weights taken twice weekly. Mice were deemed to have lethal toxicity if they lost more than $15 \%$ of starting body weight or were otherwise deemed moribund. The MTD was the highest dose administered in which all the mice in the group survived the injections.

\section{In vivo therapeutic activity}

All animal studies were approved by the University of Medicine and Dentistry of New Jersey's Institutional Animal Care and Use Committee (IACUC) and performed in accordance with the Association for Assessment and Accreditation of Laboratory Animal Care, U.S. Department of Agriculture, and Department of Health and Human Services regulations. Female $\mathrm{NCr}$ athymic nude $(n u / n u)$ mice, 5 weeks old, and SCID mice, 7 weeks old, were purchased from Taconic Farms (Hudson, NY). Two tumor models, solid and liquid cancers, were used to evaluate the efficacy and specificity of DNL-generated immunoRNases, $(\operatorname{Rap})_{2}$-E1*-(Rap) ${ }_{2}$ and $(\operatorname{Rap})_{2}-22^{*}-(\operatorname{Rap})_{2}$, as binding and nonbinding agents for MDA-MB-468 and vice versa for Daudi, respectively. For the MDA-MB-468 xenograft model, nude mice were each injected s.c. in the flank with $200 \mu \mathrm{L}$ of MDA-MB-468 cells $\left(1 \times 10^{7}\right)$ mixed 1:1 with matrigel (BD Bioscience). Once tumors reached approximately $0.2 \mathrm{~cm}^{3}$ in size, the animals were divided into three groups of 8 to 9 each. The treatment group received i.v. administration of the MTD of (Rap) $)_{2}$-E1*$(\operatorname{Rap})_{2}(20 \mu \mathrm{g}$ i.v. q4dx4), followed by a second cycle 24 days after the last injection of the first cycle. The control group received the same dose/schedule of a CD22targeting (Rap $)_{2}-22^{*}$-(Rap $)_{2}$, which served as an alternative non-specific counterpart of (Rap) $)_{2}-E 1 *-(\operatorname{Rap})_{2}$. The third group remained untreated and only received saline $(100 \mu \mathrm{l})$. After treatment commenced, mice were weighed and tumors measured weekly. For both models, tumor volume (TV) was determined by measurements in two dimensions using calipers, with volumes defined as: $L \times w^{2} / 2$, where $L$ is the longest dimension of the tumor and $w$ the shortest. When a tumor in individual mice ulcerated or exceeded $1.0 \mathrm{~cm}^{3}$ in measured volume, the animal was deemed to have succumbed to disease progression and was euthanized.

The model for disseminating human Burkitt lymphoma was established by injecting SCID mice i.v. with $1.5 \times 10^{7}$ Daudi cells. On the day cells were administered, the mice were randomized into groups of 5 each. Therapy began 7 days later. The treatment groups received $(\text { Rap })_{2}-22^{*}-(\operatorname{Rap})_{2}$ at either the MTD $(20 \mu \mathrm{g}, \mathrm{q} 4 \mathrm{dx} 4)$ or at half that dose $(10 \mu \mathrm{g} \mathrm{q} 4 \mathrm{~d} \times 4)$. For the three controls, one group received the same amount of (Rap) $)_{2}$-E1*(Rap) $)_{2}$, another group received the parental hLL2 IgG/ epratuzumab ( $25 \mu \mathrm{g}, \mathrm{q} 4 \mathrm{dx} 4)$, and the third group received only saline $(100 \mu \mathrm{L})$. Mice were deemed to have succumbed to disease progression when hind-limb paralysis developed, or if they lost more than $15 \%$ of their initial body weight, or if they became otherwise moribund.

Statistical analysis for the tumor growth data was based on AUC as well as survival time. The profile of tumor growth in each mouse was obtained through linear curve modeling. As a consequence of incompleteness of some of the growth curves (due to deaths), statistical comparisons of AUC was only performed up to the time at which the first animal within a group was euthanized due to disease progression. An $f$-test was employed to determine equality of variance between groups prior to statistical analysis of growth curves. A two-tailed $t$-test was used to assess statistical significance $(P \leq 0.05)$ between treatment groups except for the saline control in which a one-tailed $t$-test was utilized. Survival studies were analyzed from Kaplan-Meier plots (log-rank analysis), using the Prism GraphPad Software (v4.03) software package (Advanced Graphics Software, Rancho Santa Fe, CA).

\section{Additional files}

Additional file 1: Figure S1. Molecular characterization of selected DNL-Rap conjugates. A. Reducing (lanes 1-3) and non-reducing (lanes 4-6) SDS-PAGE analyses of Rap-DDD2 (lanes 1 and 4), $C_{H} 3-A D 2-l g G-h R S 7$ (lanes 2 
and 5), and (Rap) $)_{2}$-E1-(Rap) $)_{2}$ (lanes 3 and 6). B. SE-HPLC profiles of (Rap) $)_{2}-E 1$ (Rap) ${ }_{2}, C_{H} 3-A D 2-$ lgG-hRS7 (denoted as hRS7-lgG-AD2) and Rap-DDD2. C. Dynamic light scattering analysis of (Rap) ${ }_{2}-$ E1-(Rap) $)_{2}$. D. SE-HPLC profiles of $(\text { Rap })_{2}-E 1^{*}-(\text { Rap })_{2}$ and $(\operatorname{Rap})_{2}$-E1-(Rap) $)_{2}$. E. SDS-PAGE analyses of $C_{K}$-AD2-lgGhLL2, (Rap)2-22*-(Rap) 2, Rap-DDD2, (Rap) 2-22-(Rap) 2, and CH3-AD2-IgG-hLL2

Additional file 2: Figure S2. Trop-2 expression in selected breast cancer cell lines as determined by binding to hRS7. Cells were incubated without or with $10 \mu \mathrm{g} / \mathrm{mL}$ of hRS7 or hA20 lgG on ice for $45 \mathrm{~min}$ followed by FITC labeled goat anti-human IgG (GAH-FITC), and analyzed by flow cytometry. Data were processed by FlowJo software, with the MFI shown in Additional file 3: Table S1.

Additional file 3: Table S1. Surface Trop-2 expression on selective breast cancer cell lines as determined by binding to hRS7.

Additional file 4: Figure S3. In vitro cytotoxicity of (Rap) $)_{2}-E 1-(\text { Rap })_{2}$ against a variety of solid cancer lines. Cells were harvested, plated into 96-well plates, and incubated with (Rap) $)_{2}-\mathrm{E} 1-(\operatorname{Rap})_{2}$ at a final concentration ranging from 100 to $1 \times 10^{-6} \mathrm{nM}$ or 66.7 to $6.67 \times 10^{-7} \mathrm{nM}$ for a period of four doubling times, which were predetermined to be $7,5,5,8,5$, and 6 days for MDA PCa 2b, PC-3, 22Rv1, Calu-3, BxPC-3, and ME-180, respectively. After each incubation period, MTS substrate (Cell Titer $96^{\circledR}$ AQueous One Solution; Promega) was added to all the wells and the color developed was measured at 1-h intervals for up to $4 \mathrm{~h}$. Activity of test agents was calculated as a percent viability of treated cells relative to untreated cells using Microsoft Excel and Prism software ( $X=\log [X]$; non-linear regression sigmoidal dose response curves). As controls, cells were treated similarly with (Rap) 2 -22-(Rap) 2 , hRS7 lgG alone, or a combination of hRS7 lgG with either recombinant Rap (rRap, Ref. [36]) or Rap-DDD2. The EC 50 values of (Rap) $)_{2}$ E1-(Rap) 2 were determined to be $0.005,0.04,0.307,0.032,0.522$, and $>100$ nM for MDA PCa 2b, PC-3, BxPC-3, ME-180, Calu-3, and 22Rv1, respectively.

Additional file 5: Figure S4. Effect of (Rap) ${ }_{2}-\mathrm{E} 1-(\operatorname{Rap})_{2}$ on hematological cells. Minimal toxicity of (Rap) $)_{2}$-E1-(Rap) $)_{2}$ to PBMCs from two healthy donors was indicated by comparable viable and apoptotic cells with those of untreated controls.

Additional file 6: Figure S5. Tolerability of mice treated with two cycles of (Rap) $)_{2}-E 1^{*}-(\text { Rap })_{2}$ or (Rap) $)_{2}-22^{*}-(\text { Rap })_{2}$ at MTD as assessed by the percent of starting body weight.

\section{Abbreviations}

Rap: Ranpirnase; (Rap): Rap-DDD2; (Rap)2: Dimerized Rap-DDD2; DNL: DOCKAND-LOCK; TNBC: Triple-negative breast cancer; ER: Estrogen receptor; PR: Progesterone receptor; HER2: Human epidermal growth factor receptor type 2; PARP: Poly ADP ribose polymerase; mTOR: Mammalian target of rapamycin; SE-HPLC: Size-exclusion high-performance liquid chromatography.

\section{Competing interests}

All authors are employees of Immunomedics, Inc., or IBC Pharmaceuticals, Inc., or both, and have stocks or stock options of Immunomedics, Inc. IBC Pharmaceuticals, Inc. is a fully own subsidiary of Immunomedics, Inc.

\section{Authors' contributions}

$\mathrm{DL}$ designed and performed in vitro studies, analyzed the data, and drafted the manuscript. TMC designed in vivo studies and performed the statistical analysis. YW performed dynamic light scattering analysis and cell internalization assay. EAR participated in the development of methodology. DMG and CHC conceived and directed the study, and wrote the paper. All authors read and approved the final manuscript.

\section{Acknowledgements}

This work was partially supported by the U.S. NIH (grant 1R43CA180343-01 to $\mathrm{DL}$ ). The authors thank Roberto Arrojo, John Kopinski, Maria Zalath, and Gaby Terracina for excellent technical assistance.

\section{Author details}

'IBC Pharmaceuticals, Inc., Morris Plains 07950, NJ, USA. ${ }^{2}$ Immunomedics, Inc., Morris Plains 07950, NJ, USA. ${ }^{3}$ Garden State Cancer Center, Center for Molecular Medicine and Immunology, Morris Plains 07950, NJ, USA.
Received: 3 December 2013 Accepted: 26 February 2014

Published: 10 March 2014

\section{References}

1. Hutchinson L: Breast cancer: challenges, controversies, breakthroughs. Nat Rev Clin Oncol 2010, 7:669-670.

2. Siegel R, Naishadham D, Jemal A: Cancer statistics, 2013. CA Cancer J Clin 2013, 63:11-30.

3. Baselga J, Campone M, Piccart M, Burris HA 3rd, Rugo HS, Sahmoud T, Noguchi S, Gnant M, Pritchard KI, Lebrun F, Beck JT, Ito Y, Yardley D, Deleu I, Perez A, Bachelot T, Vittori L, Xu Z, Mukhopadhyay P, Lebwohl D, Hortobagyi GN: Everolimus in postmenopausal hormone-receptorpositive advanced breast cancer. N Engl J Med 2012, 366:520-529.

4. Johnston SR: New strategies in estrogen receptor-positive breast cancer. Clin Cancer Res 2010, 16:1979-1987.

5. Arteaga CL, Sliwkowski MX, Osborne CK, Perez EA, Puglisi F, Gianni L: Treatment of HER2-positive breast cancer: current status and future perspectives. Nat Rev Clin Oncol 2012, 9:16-32.

6. Higgins MJ, Baselga J: Targeted therapies for breast cancer. J Clin Invest 2011, 121:3797-3803.

7. Hudis CA, Gianni L: Triple-negative breast cancer: an unmet medical need. Oncologist 2011, 16(Suppl 1):1-11.

8. Foulkes WD, Smith IE, Reis-Filho JS: Triple-negative breast cancer. N Engl J Med 2010, 363:1938-1948

9. Irshad S, Ellis P, Tutt A: Molecular heterogeneity of triple-negative breast cancer and its clinical implications. Curr Opin Oncol 2011, 23:566-577.

10. Metzger-Filho O, Tutt A, de Azambuja E, Saini KS, Viale G, Loi S, Bradbury I, Bliss JM, Azim HA Jr, Ellis P, Di Leo A, Baselga J, Sotiriou C, Piccart-Gebhart $\mathrm{M}$ : Dissecting the heterogeneity of triple-negative breast cancer. J Clin Oncol 2012, 30:1879-1887.

11. Santana-Davila R, Perez EA: Treatment options for patients with triplenegative breast cancer. J Hematol Oncol 2010, 3:42.

12. Ardelt W, Mikulski SM, Shogen K: Amino acid sequence of an anti-tumor protein from Rana pipiens oocytes and early embryos. Homology to pancreatic ribonucleases. J Biol Chem 1991, 266:245-251.

13. Darzynkiewicz Z, Carter SP, Mikulski SM, Ardelt WJ, Shogen K: Cytostatic and cytotoxic effects of Pannon (P-30 Protein), a novel anticancer agent. Cell Tissue Kinet 1988, 21:169-182.

14. Mikulski SM, Ardelt W, Shogen K, Bernstein EH, Menduke H: Striking increase of survival of mice bearing M109 Madison carcinoma treated with a novel protein from amphibian embryos. J Natl Cancer Inst 1990, 82:151-153.

15. Rodríguez M, Torrent G, Bosch M, Rayne F, Dubremetz JF, Ribó M, Benito A, Vilanova M, Beaumelle B: Intracellular pathway of Onconase that enables its delivery to the cytosol. J Cell Sci 2007, 120:1405-1411.

16. Saxena SK, Sirdeshmukh R, Ardelt W, Mikulski SM, Shogen K, Youle RJ: Entry into cells and selective degradation of tRNAs by a cytotoxic member of the RNase A family. J Biol Chem 2002, 277:15142-15146.

17. Iordanov MS, Ryabinina OP, Wong J, Dinh TH, Newton DL, Rybak SM, Magun BE: Molecular determinants of apoptosis induced by the cytotoxic ribonuclease onconase: evidence for cytotoxic mechanisms different from inhibition of protein synthesis. Cancer Res 2000, 60:1983-1994.

18. Rybak SM, Pearson JW, Fogler WE, Volker K, Spence SE, Newton DL, Mikulski SM, Ardelt W, Riggs CW, Kung HF, Longo DL: Enhancement of vincristine cytotoxicity in drug-resistant cells by simultaneous treatment with onconase, an antitumor ribonuclease. J Natl Cancer Inst 1996, 88:747-753.

19. Michaelis M, Cinatl J, Anand P, Rothweiler F, Kotchetkov R, von Deimling A Doerr HW, Shogen K, Cinatl J Jr: Onconase induces caspase-independent cell death in chemoresistant neuroblastoma cells. Cancer Lett 2007, 250(1):107-116.

20. Reck MKM, Jassem J, Eschbach C, Kozielski J, Costanzi JJ, Gatzemeier U, Shogen K, von Pawel J: Randomized, multicenter phase III study of ranpirnase plus doxorubicin (DOX) versus DOX in patients with unresectable malignant mesothelioma (MM). J Clin Oncol 2009, 27:15s.

21. Mikulski SM, Costanzi JJ, Vogelzang NJ, McCachren S, Taub RN, Chun H, Mittelman A, Panella T, Puccio C, Fine R, Shogen K: Phase II trial of a single weekly intravenous dose of ranpirnase in patients with unresectable malignant mesothelioma. J Clin Oncol 2002, 20:274-281.

22. Mikulski S, Grossman A, Carter P, Shogen K, Costanzi J: Phase-I human clinical-trial of onconase(r) (p-30 protein) administered intravenously on 
a weekly schedule in cancer-patients with solid tumors. Int J Oncol 1993, 3:57-64.

23. Stepan LP, Trueblood ES, Hale K, Babcook J, Borges L, Sutherland CL: Expression of Trop2 cell surface glycoprotein in normal and tumor tissues: potential implications as a cancer therapeutic target. J Histochem Cytochem 2011, 59:701-710.

24. Wang J, Day R, Dong Y, Weintraub SJ, Michel L: Identification of Trop-2 as an oncogene and an attractive therapeutic target in colon cancers. Mol Cancer Ther 2008, 7:280-285.

25. Stoyanova T, Goldstein AS, Cai H, Drake JM, Huang J, Witte ON: Regulated proteolysis of Trop2 drives epithelial hyperplasia and stem cell selfrenewal via beta-catenin signaling. Genes Dev 2012, 26:2271-2285.

26. Huang H, Groth J, Sossey-Alaoui K, Hawthorn L, Beall S, Geradts J: Aberrant expression of novel and previously described cell membrane markers in human breast cancer cell lines and tumors. Clin Cancer Res 2005, 11:4357-4364

27. Fang YJ, Lu ZH, Wang GQ, Pan ZZ, Zhou ZW, Yun JP, Zhang MF, Wan DS: Elevated expressions of MMP7, TROP2, and survivin are associated with survival, disease recurrence, and liver metastasis of colon cancer. Int $J$ Colorectal Dis 2009, 24:875-884.

28. Ohmachi T, Tanaka F, Mimori K, Inoue H, Yanaga K, Mori M: Clinical significance of TROP2 expression in colorectal cancer. Clin Cancer Res 2006, 12:3057-3063.

29. Fong D, Spizzo G, Gostner JM, Gastl G, Moser P, Krammel C, Gerhard S, Rasse M, Laimer K: TROP2: a novel prognostic marker in squamous cell carcinoma of the oral cavity. Mod Pathol 2008, 21:186-191.

30. Cubas R, Li M, Chen C, Yao Q: Trop2: a possible therapeutic target for late stage epithelial carcinomas. Biochim Biophys Acta 2009, 1796:309-314.

31. Chang CH, Rossi EA, Goldenberg DM: The dock and lock method: a novel platform technology for building multivalent, multifunctional structures of defined composition with retained bioactivity. Clin Cancer Res 2007, 13(18 Pt 2):5586s-5591s.

32. Rossi EA, Goldenberg DM, Cardillo TM, McBride WJ, Sharkey RM, Chang CH Stably tethered multifunctional structures of defined composition made by the dock and lock method for use in cancer targeting. Proc Natl Acad Sci U S A 2006, 103:6841-6846.

33. Rossi EA, Goldenberg DM, Cardillo TM, Stein R, Chang CH: CD20-targeted tetrameric interferon-alpha, a novel and potent immunocytokine for the therapy of B-cell lymphomas. Blood 2009, 114:3864-3871.

34. Chang CH, Gupta P, Michel R, Loo M, Wang Y, Cardillo TM, Goldenberg DM: Ranpirnase (frog RNase) targeted with a humanized, internalizing, antiTrop-2 antibody has potent cytotoxicity against diverse epithelial cancer cells. Mol Cancer Ther 2010, 9:2276-2286.

35. Rossi EA, Chang CH, Cardillo TM, Goldenberg DM: Optimization of multivalent bispecific antibodies and immunocytokines with improved in vivo properties. Bioconjug Chem 2013, 24:63-71.

36. Newton DL, Hansen HJ, Mikulski SM, Goldenberg DM, Rybak SM: Potent and specific antitumor effects of an anti-CD22-targeted cytotoxic ribonuclease: potential for the treatment of non-Hodgkin lymphoma. Blood 2001, 97:528-535.

37. Chang CH, Sapra P, Vanama SS, Hansen HJ, Horak ID, Goldenberg DM: Effective therapy of human lymphoma xenografts with a novel recombinant ribonuclease/anti-CD74 humanized IgG4 antibody immunotoxin. Blood 2005, 106:4308-4314.

38. Cardillo TM, Govindan SV, Sharkey RM, Trisal P, Goldenberg DM: Humanized anti-Trop-2 lgG-SN-38 conjugate for effective treatment of diverse epithelial cancers: preclinical studies in human cancer xenograft models and monkeys. Clin Cancer Res 2011, 17:3157-3169.

39. Rossi EA, Goldenberg DM, Cardillo TM, Stein R, Wang Y, Chang CH: Novel designs of multivalent anti-CD20 humanized antibodies as improved lymphoma therapeutics. Cancer Res 2008, 68:8384-8392.

40. Rossi DL, Rossi EA, Goldenberg DM, Chang CH: A new mammalian host cell with enhanced survival enables completely serum-free development of high-level protein production cell lines. Biotechnol Prog 2011, 27:766-775.

doi:10.1186/1476-4598-13-53

Cite this article as: Liu et al:: Trop-2-targeting tetrakis-ranpirnase has potent antitumor activity against triple-negative breast cancer. Molecular Cancer 2014 13:53.

\section{Submit your next manuscript to BioMed Central and take full advantage of:}

- Convenient online submission

- Thorough peer review

- No space constraints or color figure charges

- Immediate publication on acceptance

- Inclusion in PubMed, CAS, Scopus and Google Scholar

- Research which is freely available for redistribution 